\title{
Interaction between Track and Long-Span Cable-Stayed Bridge: Recommendations for Calculation
}

\author{
Kaize Xie, ${ }^{1,2}$ Weigang Zhao, ${ }^{1}$ Xiaopei Cai $\mathbb{D},{ }^{2,3}$ Ping Wang, ${ }^{4}$ and Jia Zhao ${ }^{1}$ \\ ${ }^{1}$ State Key Laboratory of Mechanical Behavior and System Safety of Traffic Engineering Structures, \\ Shijiazhuang Tiedao University, Shijiazhuang 050043, China \\ ${ }^{2}$ Beijing Engineering and Technology Research Center of Rail Transit Line Safety and Disaster Prevention, Beijing 100044, China \\ ${ }^{3}$ School of Civil Engineering, Beijing Jiaotong University, Beijing 100044, China \\ ${ }^{4}$ MOE Key Laboratory of High-Speed Railway Engineering, Southwest Jiaotong University, Chengdu 610031, China
}

Correspondence should be addressed to Xiaopei Cai; xpcai@bjtu.edu.cn

Received 4 January 2020; Revised 19 April 2020; Accepted 27 April 2020; Published 11 May 2020

Academic Editor: Giovanni Lancioni

Copyright (c) 2020 Kaize Xie et al. This is an open access article distributed under the Creative Commons Attribution License, which permits unrestricted use, distribution, and reproduction in any medium, provided the original work is properly cited.

\begin{abstract}
Geometric nonlinearity (GN) and initial internal forces (IIFs) are the basic characteristics of cable-stayed bridges, but now there is no effective method for analyzing the effect of them on bridge-track interaction of continuous welded rail (CWR) on cable-stayed bridge. A method for reconstructing the displacement-force curve of ballast longitudinal resistance was put forward according to the deformation of cable-stayed bridges under the completed bridge state. A feasibility study on the method was conducted via two aspects of the force and deformation of CWR on a $5 \times 40 \mathrm{~m}$ single-line simple-supported beam bridge with initial deformation. With the multi-element modeling method and the updated Lagrangian formulation method, a rail-beam-cable-tower 3D calculation model considering the GN and IIFs of cable-stayed bridge was established. Taking a $(140+462+1092+462+140 \mathrm{~m})$ twin-tower cable-stayed bridge as an example, the impacts of GN and IIFs on bridge-track interaction were comparatively analyzed. The results show that the method put forward to reconstruct ballast longitudinal resistance can prevent the impact of initial deformation of bridge and makes it possible to consider the effect of IIFs of cable-stayed bridge on bridge-track interaction. The GN and IIFs play important roles in the calculation of rail longitudinal force due to vertical bending of bridge deck under train load and the variance of cable force due to negative temperature changes in bridge decks and rails with rail breaking, and the two factors can reduce rail longitudinal force and variance of cable force by $11.8 \%$ and $14.6 \%$, respectively. The cable-stayed bridge can be simplified as a continuous beam bridge with different constraints at different locations, when rail longitudinal force due to positive temperature changes in bridge deck and train braking is calculated.
\end{abstract}

\section{Introduction}

The construction of cable-stayed bridges has been booming since World War II, due to their reasonable force structure, ease construction, elegant shape, and strong span capability. The main spans of cable-stayed bridges have increased in length from the $182.6 \mathrm{~m}$ span of the Stromsund bridge to the 1-104 m span of Russky Island-the longest main span of a cable-stayed bridge in the world. Cablestayed bridges with main spans less than $1,400 \mathrm{~m}$ are of good economic efficiency and better than suspension bridges in terms of rigidity and wind resistance [1-3]. Cable-stayed bridges also are also more suitable for carrying rail traffic because of the high stability. Therefore, cable-stayed bridges have gained increasing acceptance from railway bridge engineers [4]. One current example is the Shanghai-Nantong Yangtze River Bridge designed for both road and rail traffic. When completed, it will be the longest cable-stayed bridge for both road and rail traffic in the world. With the increasing of spans of cable-stayed bridges, the geometric nonlinearity (GN) effect will be more obvious. The GN effect mainly consists of the cable sag effect from the weight of the stay cables, the large displacement effect caused by the main beams, and the beam-column effect caused by the bending-compression of the main beams and bridge towers [5]. 
Around the world, researchers are conducting extensive researches on the train-bridge-track dynamic interaction to ensure the safety running of train [6-8] and bridge-track interaction to design continuous welded rail (CWR) on bridges [9-11]. However, the application of cable-stayed bridges in railway field occurred relatively recently, so few studies on bridge-track interaction of CWR on cable-stayed bridges have been presented, let alone research findings on the impact of GN and initial internal forces (IIFs) of cablestayed bridges on bridge-track interaction. Petrangeli established a 2D model for longitudinal bridge-track interaction of CWR on a cable-stayed bridge (span: $104+192+104 \mathrm{~m}$ ) using the SAP2000 software and studied the distribution of rail longitudinal force [12]. The research group led by Wang et al., by taking a twin-tower two-cableplane cable-stayed bridge (span: $36+96+228+$ $96+36 \mathrm{~m}$ ) of high-speed railway as an example, also established a 2D model through simplifying the main beam into beam elements and created a calculation program with the finite element software ANSYS [13-15]. The research group led by Dai and Yan also studied the bridge-track interaction of CWR on a cable-stayed bridge (span: $32+80+112 \mathrm{~m}$ ) and analyzed the impact of factors such as loading-history, pile-soil effect, and seismic load on bridgetrack interaction according to an integrated calculation model. They also presented the superposition mode of loads on cable-stayed bridges when checking the stress in rail as well as the factors to be considered in checking the rail broken gap [16-18]. Zheng et al. analyzed the impact of loading-history on bridge-track interaction with a $2 \mathrm{D}$ model of a cable-stayed bridge (span: $80+140+80 \mathrm{~m}$ ) [19]. Li et al. established a 3D cable-stayed bridge model of the twin-tower three-cable-plane Anqing Yangtze River Bridge (span: $101.5+188.5+580.0+217.5+159.5+116.0 \mathrm{~m}$ ) and guided the design of CWR on the bridge [20]. Cai et al. discussed the effectiveness of different measures to relieve bridge-track interaction with an integrated model of CWR on a twin-tower eight-span cable-stayed bridge (span: $2 \times 50+224+672+174+3 \times 50 \mathrm{~m}$ ) [21]. In these studies, the modulus of elasticity of the stay cables was modified according to the Ernst equation to consider the cable sag effect [22]. However, there are still two shortcomings in these models:

(1) The stay cable force will continuously increase as the length of span increases, so it is still difficult to accurately simulate the cable sag effect even when the calculations are performed according to the modified modulus of elasticity.

(2) The impacts of other nonlinearity factors and IIFs are not fully considered in these models. These shortcomings are obstacles not only in studying the bridge-track interaction of CWR on cable-stayed bridges, but also in correctly analyzing the impact of the bridge-track interaction on cable-stayed bridges.

Therefore, a rail-beam-cable-tower 3D model, with a new method for reconstructing the ballast longitudinal resistance curve and a suitable calculation method, is established to study the impacts of GN and IIFs on the bridge-track interaction of CWR on cable-stayed bridge.

\section{Bridge-Track Connection}

The rail of CWR on the cable-stayed bridge is locked after Phase II dead load (including the weight of rail) is exerted on the bridge, so Phase II dead load is involved in the analysis of completed state of the cable-stayed bridge [23, 24], but this does not affect CWR on the bridge. After locking the rail, the IIFs caused by the dead load will impact bridge-track interaction by changing the mechanical characteristics of the bridge under other loads. However, due to the limitations of the original model and analysis method, it is difficult to avoid the impact of Phase II dead load on CWR when considering IIFs. Based on the basic principle of bridge-track interaction, this paper presents a new method for reconstructing the ballast longitudinal resistance curve to make it possible.

\subsection{New Method for Reconstructing Ballast Longitudinal} Resistance Curve. The ballast longitudinal resistance in the above calculation models of CWR on bridges is mainly simulated with nonlinear springs [10-21]; the displacementforce $(D-F)$ curves of the ballast longitudinal resistance are expressed by the solid lines shown in Figure 1. Suppose that the longitudinal displacement of a bridge node obtained from the completion calculation of a cable-stayed bridge is $a$; in order to prevent the impact of the completion calculation on bridge-track interaction, the $D-F$ curves of nonlinear springs connected with the bridge node are expressed by the dash lines shown in Figure 1; the mathematical model is expressed by

$$
F= \begin{cases}F_{\max }, & D \geq a+u, \\ \frac{F_{\max }}{u}(D-a), & a-u<D<a+u, \\ -F_{\max }, & D \leq a-u,\end{cases}
$$

where $D$ is bridge-track relative displacement, $F$ is the value of ballast longitudinal resistance, $a$ represents the longitudinal displacement of the cable-stayed bridge nodes under completion calculation, and $F_{\max }$ and $u$ are the maximum force and yield displacement of ballast longitudinal resistance. For ballast track, the resistance to the longitudinal displacement of the rail is generally greater than the resistance of sleeper in ballast [25], so the resistance of sleeper in ballast plays a controlling role in the research of bridge-track interaction. According to the code of China [26], $F_{\max }$ and $u$ are $15.0 \mathrm{kN} /(\mathrm{m} \cdot$ rail $)$ and $2.0 \mathrm{~mm}$ when unloaded and $23.2 \mathrm{kN} /(\mathrm{m} \cdot$ rail) and $2.0 \mathrm{~mm}$ under loaded condition.

2.2. Feasibility Verification. In order to verify the feasibility and accuracy of the new method for reconstructing ballast longitudinal resistance curve, the CWR on a $5 \times 40 \mathrm{~m}$ singleline simple-supported beam bridge is taken as an example. Figure 2 shows the arrangement of spans and bearings. In 


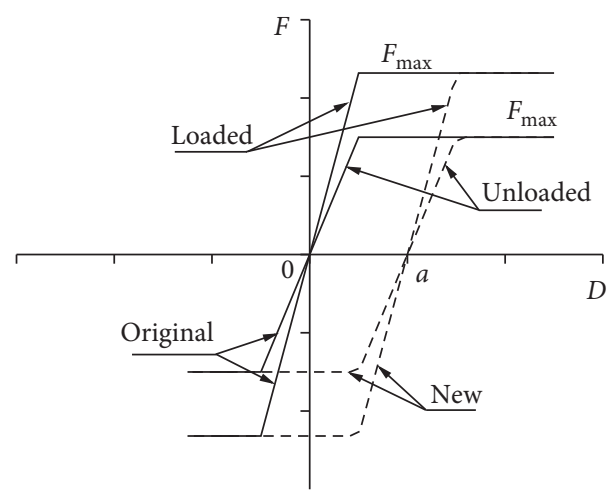

FIgURE 1: $D-F$ curves of ballast longitudinal resistance.

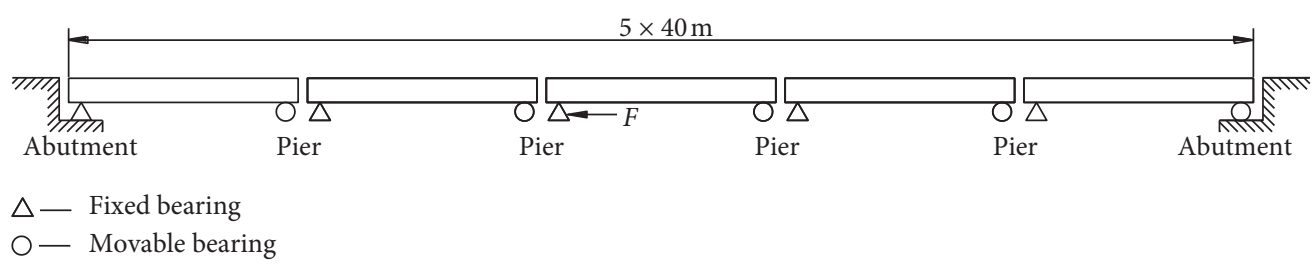

Figure 2: Arrangement of spans and bearings.

order to eliminate the boundary effect, $150 \mathrm{~m}$ subgrades are built at the exterior sides of the two abutments. The longitudinal stiffness of the abutments and piers is $1500 \mathrm{kN} / \mathrm{cm}$ and $340 \mathrm{kN} / \mathrm{cm}$, respectively. In order to simulate the longitudinal displacement caused by the completion calculation of the cable-stayed bridge before locking the rail of CWR, a longitudinal force of $102 \mathrm{kN}$ (longitudinal displacement of the bridge: $102 \mathrm{kN} / 340 \mathrm{kN} / \mathrm{cm}=0.3 \mathrm{~cm}$, i.e., $3.0 \mathrm{~mm}$ ) is exerted on the top of the second pier shown in Figure 2. When considering the longitudinal displacement of $3.0 \mathrm{~mm}$ in calculation, it is called displacement of bridge condition. If there is no displacement of bridge before locking the rail in the following calculation, it is called normal condition. The reconstructed ballast longitudinal resistance curve is used under displacement of bridge condition.

As the longitudinal displacement of the third span occurs before locking the rail, this displacement will not affect the rail longitudinal force according to the principle of bridge-track interaction. The rail longitudinal force should be the same under displacement of bridge condition and normal condition. However, the bridge-track relative displacement should differ in the third span. The following shows the feasibility and accuracy analysis. According to the different loads, the calculation is divided into four conditions. The first kind of load is positive temperature changes in bridge decks. The second kind of load is vertical bending of bridge deck under train load. The third kind of load is the breaking and acceleration of train. The last is negative temperature changes in bridge decks and rails with rail breaking. Two types of train loads are considered in the study under bending and braking conditions: ZK live load, which is representative of mixed passenger and freight traffic up to $200 \mathrm{~km} / \mathrm{h}$, and CR live load, which is representative of passenger traffic up to $350 \mathrm{~km} / \mathrm{h}$. For details, see Figure 3 .
(1) Actions due to positive temperature changes in bridge decks: Figure 4 shows the rail longitudinal force and bridge-track relative displacement when the temperature of bridges rises by $15 \mathrm{~K}$. Relative displacement difference is obtained by subtracting bridge-track relative displacement of normal condition from displacement of bridge condition.

There exists no error in the data of $3.0 \mathrm{~mm}$ of the third span, so the reconstructed $D-F$ curve of ballast longitudinal resistance considering the $3.0 \mathrm{~mm}$ is also accurate. The rail longitudinal force under displacement of bridge condition perfectly matches that under normal condition as shown in Figure 4. The bridge-track relative displacement curves of the two conditions can also coincide with each other except the scope of the third span, but the difference is equal to the initial displacement of $3.0 \mathrm{~mm}$ which is set before. The numerical results agree with the previous theoretical analysis, so it can be said that the method for reconstructing ballast longitudinal resistance curve can prevent the effect of initial deformation of bridge on bridge-track interaction due to positive temperature changes in bridge decks.

(2) Actions due to vertical bending of bridge deck under train load: Considering the full bridge arrangement of train load, $\mathrm{ZK}$ live load is adopted (see Figure 3(b)). The rail longitudinal force and bridgetrack relative displacement are shown in Figure 5.

According to the calculation results of Figure 5, the rail longitudinal force and bridge-track relative displacement of the third span coincide with those induced by positive temperature changes in bridge decks, which also verifies that this new method can 


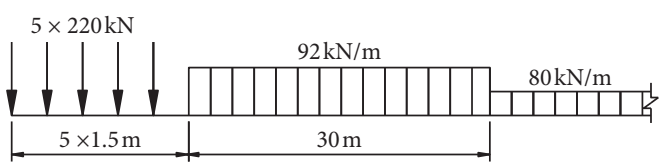

(a)

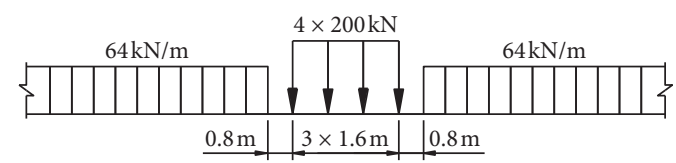

(b)

FIgURE 3: Live load. (a) ZK live load. (b) CR live load.

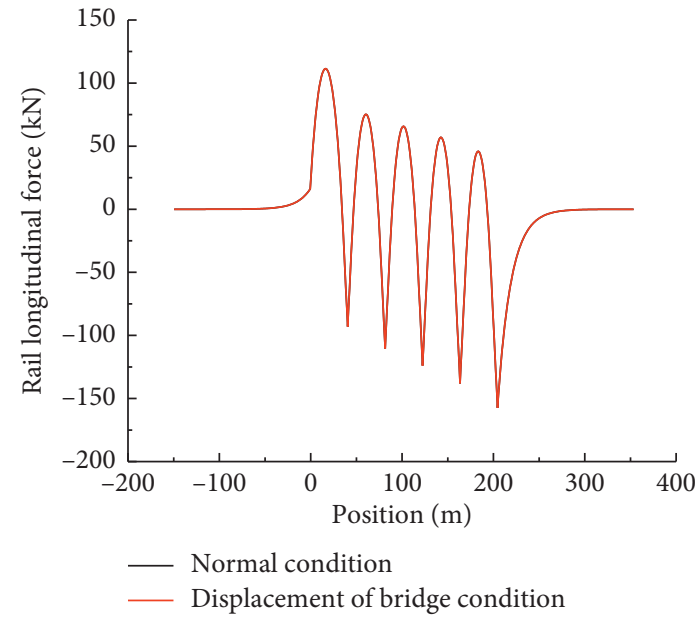

(a)

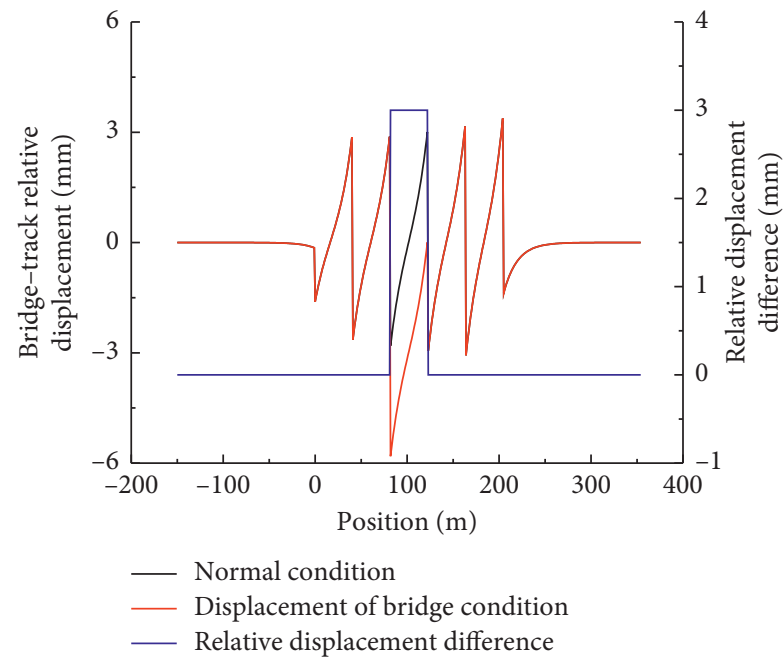

(b)

Figure 4: Verification results due to positive temperature changes in bridge decks. (a) Rail longitudinal force. (b) Displacement.

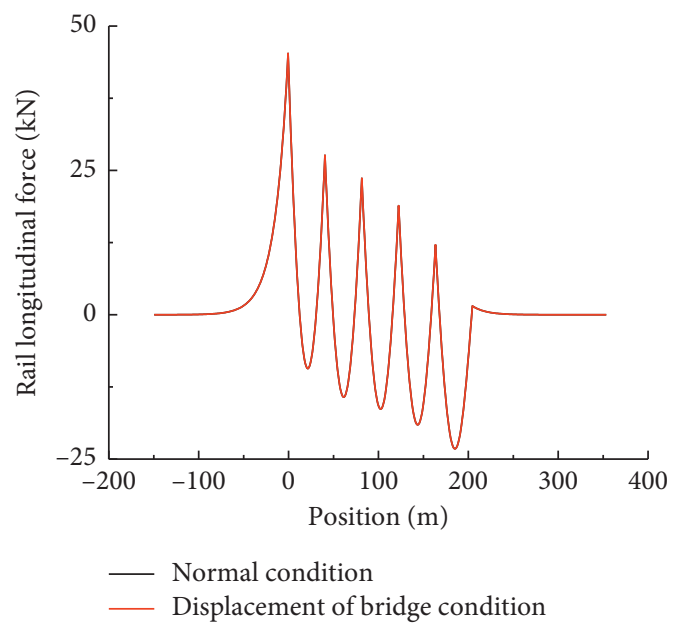

(a)

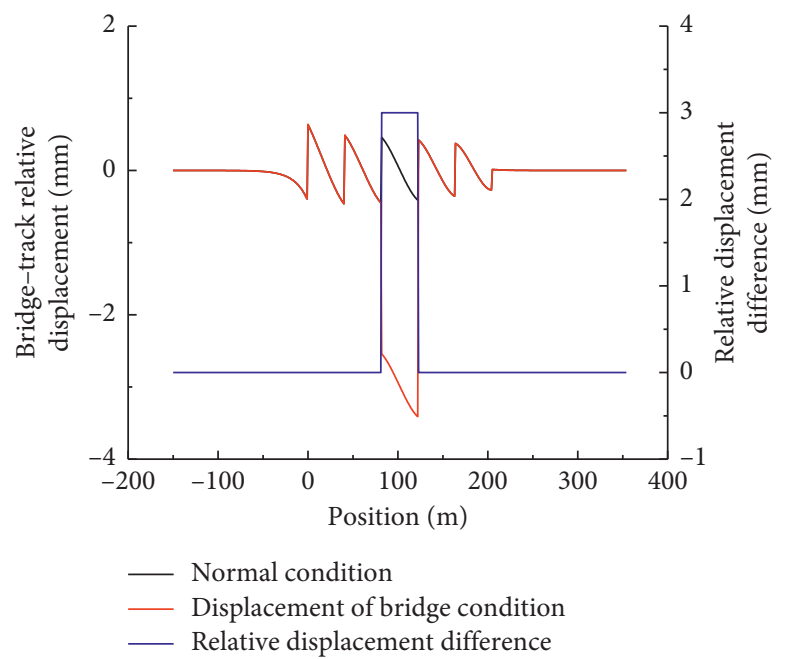

(b)

Figure 5: Verification results due to vertical bending of bridge deck under train load. (a) Rail longitudinal force; (b) displacement.

be used when vertical bending of bridge deck under train load is considered.

(3) Actions due to breaking and acceleration of train: A train entering the bridge from the left abutment covers the five-span simple-supported beam bridges completely. ZK live load is still adopted, and the wheel-rail adhesion coefficient is 0.164 [26].
Figures 6(a) and 6(b), respectively, show the rail longitudinal force and bridge-track relative displacement.

As shown in Figure 6, the results are the same as those due to the positive temperature changes in bridge deck and vertical bending of bridge decks under train load, verifying that the method can be 


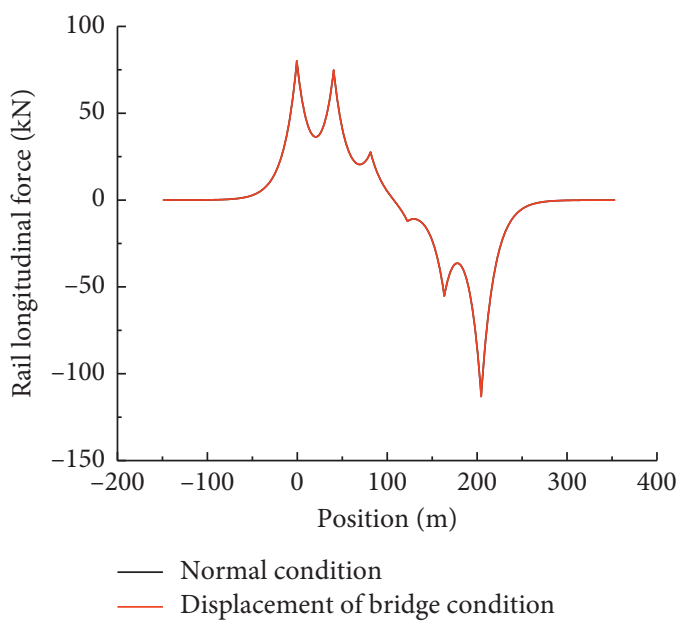

(a)

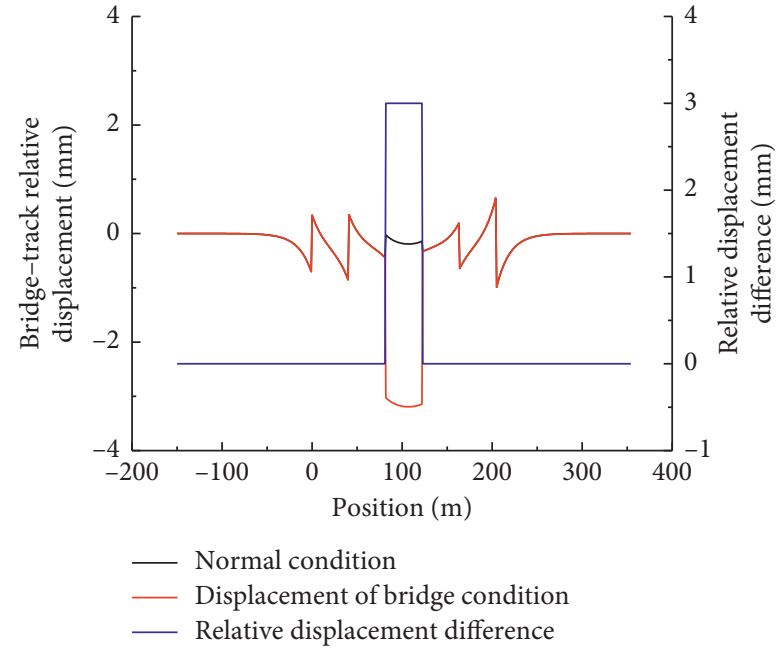

(b)

FIgURE 6: Verification results due to the breaking and acceleration of train. (a) Rail longitudinal force. (b) Displacement.

used for calculation when breaking and acceleration of train are considered.

(4) Actions due to negative temperature changes in bridge decks and rails with rail breaking: The rail breaking is preset at the position with the maximum rail longitudinal force induced by the positive temperature changes in bridge decks, i.e., it shows the location of rail breaking. According to the code [26], either of two rails on the bridge is considered broken. Figures 7 (a) and 7(b) show the rail longitudinal force and bridge-track relative displacement when the temperatures of the bridge and rail are decreased by $15 \mathrm{~K}$ and $40 \mathrm{~K}$, respectively. In Figure $7, N, D$, and RDD stand for normal condition, displacement of bridge condition, and relative displacement difference.

As shown in Figure 7, the method can be used to prevent the initial displacement of the bridge from affecting bridgetrack interaction for both the broken and unbroken rails, verifying the feasibility of the method when negative temperature changes in bridge decks and rails with rail breaking is considered.

According to the results of the calculations, the method for reconstructing ballast longitudinal resistance curve presented in this paper can be used to prevent the initial displacement of the bridge from affecting the bridge-track interaction under the four calculation conditions; therefore, it is suitable for completion calculations of cablestayed bridges. The same longitudinal displacement of the entire bridge is considered in the verification model, so when it is used to analyze the bridge-track interaction of CWR on a cable-stayed bridge, the actual longitudinal displacement of bridge nodes should be considered. Different $D-F$ curves can be established by changing parameter $a$ of (1).

\section{Model of CWR on a Cable-Stayed Bridge and Calculation Parameters}

3.1. Model of CWR on a Cable-Stayed Bridge. The existing models for analyzing the bridge-track interaction of CWR on cable-stayed bridges are always $2 \mathrm{D}$ models, which greatly simplify the complicated space structure of cable-stayed bridges. Therefore, on the one hand, it is difficult for them to correctly reflect the actual mechanical behavior of cablestayed bridges, especially when GN is considered. On the other hand, it is also difficult to analyze the impact of IIFs of cable-stayed bridges on bridge-track interaction with a simplified model. Thus, a rail-beam-cable-tower 3D model is established to analyze bridge-track interaction of CWR on a cable-stayed bridge. For details, see Figure 8.

Different structures in the model are simulated with different types of elements according to their mechanical characteristics. The upper/lower chord members, web members, longitudinal beams, transverse beams, sway bracings, U-ribs, and rails are simulated with beam elements. The deck slabs are simulated with shell elements. In order to analyze the cable sag effect, a single stay cable is simulated with several bar elements connected end-to-end. For a cablestayed bridge, the cable force of some stay cables might decrease under load; however, it will not decrease to zero, so it is not necessary to consider the nonlinear characteristics. The bridge tower is discretized and simulated with short equal-section beam elements via simplification. In order to simulate the connection between stay cables and towers, the sections of the bridge tower connected to the stay cables are simulated with rigid beam elements. The damping devices and ballast longitudinal resistance are simulated with special nonlinear springs. The damping devices are only used when breaking and acceleration of train are considered, so their $D$ $F$ curve should be updated according to (1). 


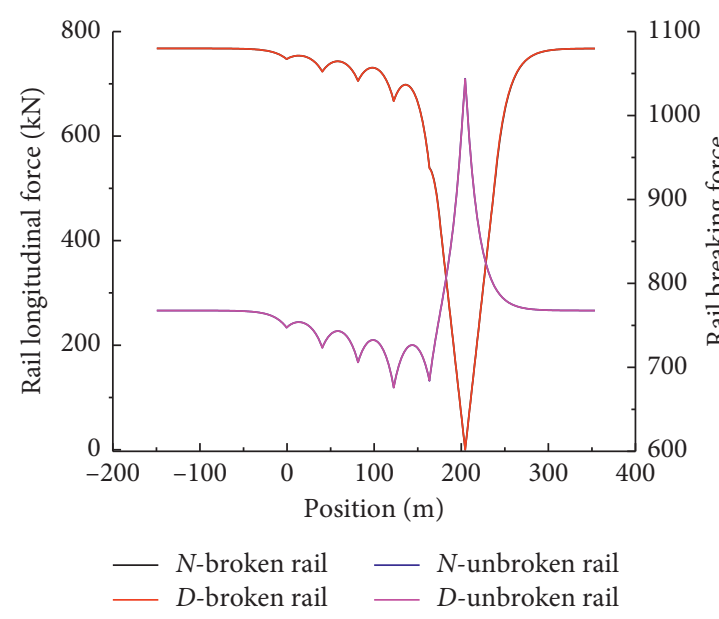

(a)

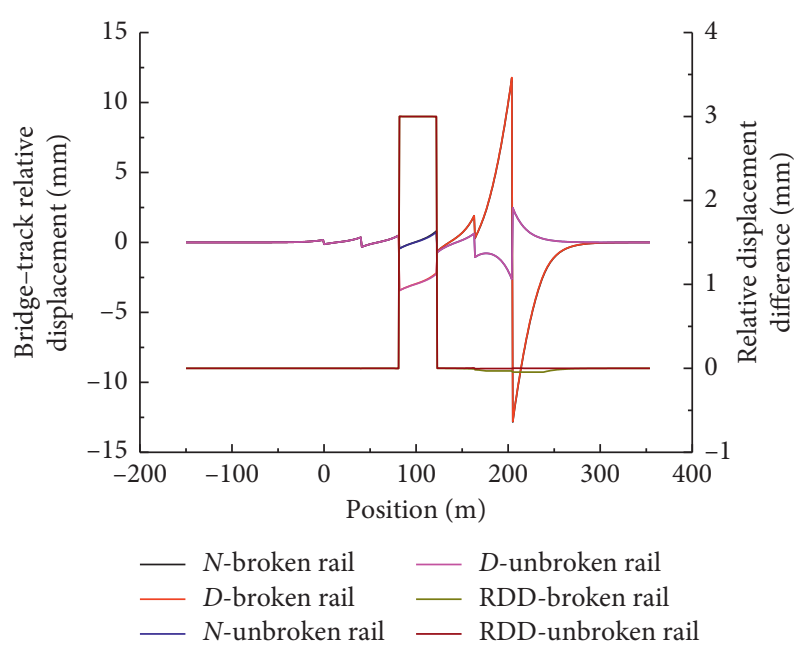

(b)

FIGURE 7: Verification results due to negative temperature changes in bridge decks and rails with rail breaking. (a) Rail longitudinal force. (b) Displacement.

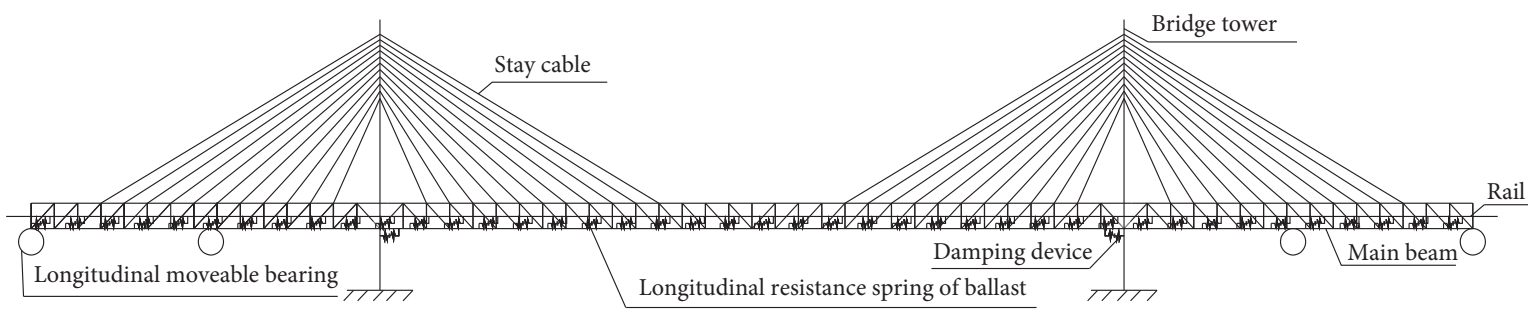

(a)

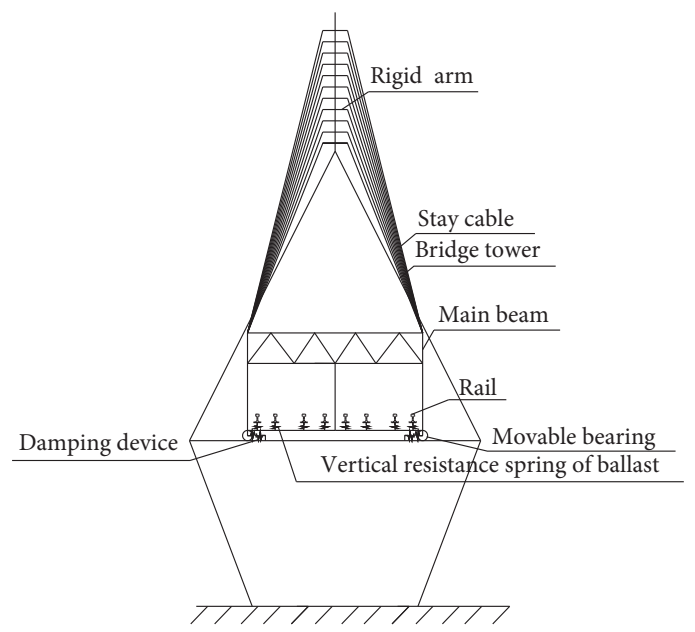

(b)

Figure 8: A rail-beam-cable-tower 3D model. (a) Front view. (b) Cross section at the location of bridge tower.

Each calculation of the geometric positions of different nodes of the model is updated according to the Updated Lagrangian formulation (UL) method [27], based on which new stiffness matrices are formed to consider the beamcolumn effect and the large deformation effect within the model. In addition, according to the impact of the initial internal force on the stiffness matrices, the model can be used to study the impact of GN and IIFs on bridge-track interaction of CWR on cable-stayed bridges.

\subsection{Calculation Parameters}

3.2.1. Engineering Profile. A twin-tower three-cable-plane cable-stayed bridge in China is taken as an example to 
explain the impact of GN and IIFs of cable-stayed bridges on bridge-track interaction of CWR. The span arrangement is $140+462+1,092+462+140 \mathrm{~m}$. The main beam is an $N-$ shaped truss with a height and width of $16 \mathrm{~m}$ and $35 \mathrm{~m}$, respectively. The deck supports four-track railway. Two lines are mixed passenger and freight railways, while the other two are passenger dedicated lines. The towers are reinforced concrete structures, the part of which on the deck is inverse $Y$-shape, while the towers column beneath the deck is diamond-shaped. The height of towers on the bearing platform is $325 \mathrm{~m}$. The stay cables are comprised of parallel $7 \mathrm{~mm}-$ diameter wire ropes. The whole bridge has 432 stay cables (one cable plane: $4 \times 36=144$ cables). The maximum length of a single cable is over $500 \mathrm{~m}$. The bridge is a separate towerbeam and consolidated tower-pier form. Bearings and damping devices are set between the towers and beam. See Figure 9 for the general layout of the bridge and a cross section of the main beam.

3.2.2. Parameters. The paper mainly focuses on the influence of GN and IIFs of the cable-stayed bridge on bridgetrack interaction of CWR. In order to facilitate the comparison of different analytical states, rail expansion joints are temporarily ignored. The approach spans at both sides of the cable-stayed bridge are simplified as $10 \times 32 \mathrm{~m}$ simplesupported concrete beam bridges. The height, vertical moment of inertia, and transverse moment of inertia of the bridge profile are $2.6 \mathrm{~m}, 10.236 \mathrm{~m}^{4}$, and $88.522 \mathrm{~m}^{4}$, respectively. The longitudinal stiffness of the piers of the bridges is $360 \mathrm{kN} / \mathrm{cm}$, and the stiffness of the abutments is $3000 \mathrm{kN} / \mathrm{cm}$. The fixed bearings for the simple-supported beams at each side are set apart from the cable-stayed bridge. And $150 \mathrm{~m}$ subgrades are built at the exterior sides. The longitudinal stiffness of the damping devices is simplified to $200 \mathrm{kN} / \mathrm{mm}$.

The cable-stayed bridge and its approach spans are laid with ballast track using CHN60 rail. The area, vertical moment of inertia, and transverse moment of inertia of the rail profile are $77.45 \mathrm{~cm}^{2}, 3,217 \mathrm{~cm}^{4}$, and $524 \mathrm{~cm}^{4}$, respectively. Type-III sleeper is selected, and sleeper spacing is $60 \mathrm{~cm}$. The length of sleepers is $260 \mathrm{~cm}$. The height and top and bottom width of middle section of sleeper are $18.5 \mathrm{~cm}$, $22.0 \mathrm{~cm}$, and $28.0 \mathrm{~cm}$, respectively. The elastic Type-II fastener which matches the sleeper is used, and the longitudinal resistance of the fastener is demanded to exceed $16.0 \mathrm{kN}$. The ballast bed thickness is up to $35 \mathrm{~cm}$. The temperature variation amplitudes of the steel beams, concrete approach spans, and rail mainly considered are $25 \mathrm{~K}, 15 \mathrm{~K}$, and $30 \mathrm{~K}$, respectively. The impact of temperature changes of stay cables and bridge towers on bridge-track interaction is ignored for the purpose of this study. The lower deck has fourtrack railway, in which the train load is subject to CR live load on two lines and $\mathrm{ZK}$ live loading on the other two.

\section{Calculation Conditions}

A completion calculation of the cable-stayed bridge is needed to determine the IIFs and the longitudinal displacement of bridge nodes. The displacement can be used to update the new ballast longitudinal resistance curves for evaluating the impact of IIFs of the bridge on CWR under different calculation conditions. The results of the new and original ballast longitudinal resistance curves are shown in Figure 10. The variation of cable force is the force corresponding to the dead load only.

As shown in Figure 10(a), the rail longitudinal force corresponding to the new curve fluctuates near zero. The maximum value is $8.1 \mathrm{kN}$, because there exist data truncation errors in the longitudinal displacement $a$ of bridge nodes for reconstructing the new ballast longitudinal resistance curves. The original curve can lead to extremely high rail longitudinal force, the amplitude of which can reach up to $2,057.7 \mathrm{kN}$. Therefore, if the original curve is used for the completion calculation of the cable-stayed bridge, the bridge-track interaction will be different from the actual, which will also have an impact on the initial state of the cable-stayed bridge itself; see Figure 10(b). According to Figure 10(b), the result of the new curve coincides with zero, while the result of the original curve differs from zero to a certain extent.

In summary, the reconstructed ballast longitudinal resistance curves can be used not only to prevent the completion calculation of the cable-stayed bridge from bridgetrack interaction, but also to ensure the correctness of the completion calculation.

In order to compare the impact of GN and IIFs of the cable-stayed bridge on bridge-track interaction, two analytical states shown in Table 1 are adopted.

\subsection{Actions due to Positive Temperature Changes in Bridge} Decks. Figures 11(a) and 11(b) show the rail longitudinal force and bridge longitudinal displacement when the temperatures of the cable-stayed bridge and approach spans rise by $25 \mathrm{~K}$ and $15 \mathrm{~K}$, respectively.

As shown in Figure 11(a), the distributions of rail longitudinal force obtained under the two analysis states are the same, and the rail longitudinal forces at different positions are almost the same. Therefore, GN and IIFs of the cable-stayed bridge have little impact on bridge-track interaction induced by positive temperature changes in bridge decks.

According to bridge longitudinal displacement shown in Figure 11(b), the cable-stayed bridge expands towards both sides, taking the position near the midspan as the fixed point in both analysis states. This indicates that the IIFs of stay cables and steel trusses have little impact on the bridge expansion. The expansion of $317.2 \mathrm{~mm}$ at the beam end due to the constraint of stay cables is less than $338.1 \mathrm{~mm}$ $\left(2,296 \mathrm{~m} / 2 \times 1.18 \times 10^{-5} / \mathrm{K} \times 25 \mathrm{~K}=0.3381 \mathrm{~m}\right)$ due to condition of freedom. Therefore, if the distribution of rail longitudinal force is to be analyzed, the cable-stayed bridge can be simplified as a two-span continuous beam bridge with a longitudinal constrain at the midspan and expandable beam ends at both sides. The rail longitudinal force of the simplified model is shown in Figure 11(a), and the maximum force is $2,557.1 \mathrm{kN}$, increasing by $73.1 \mathrm{kN}$ and $81.3 \mathrm{kN}$, 


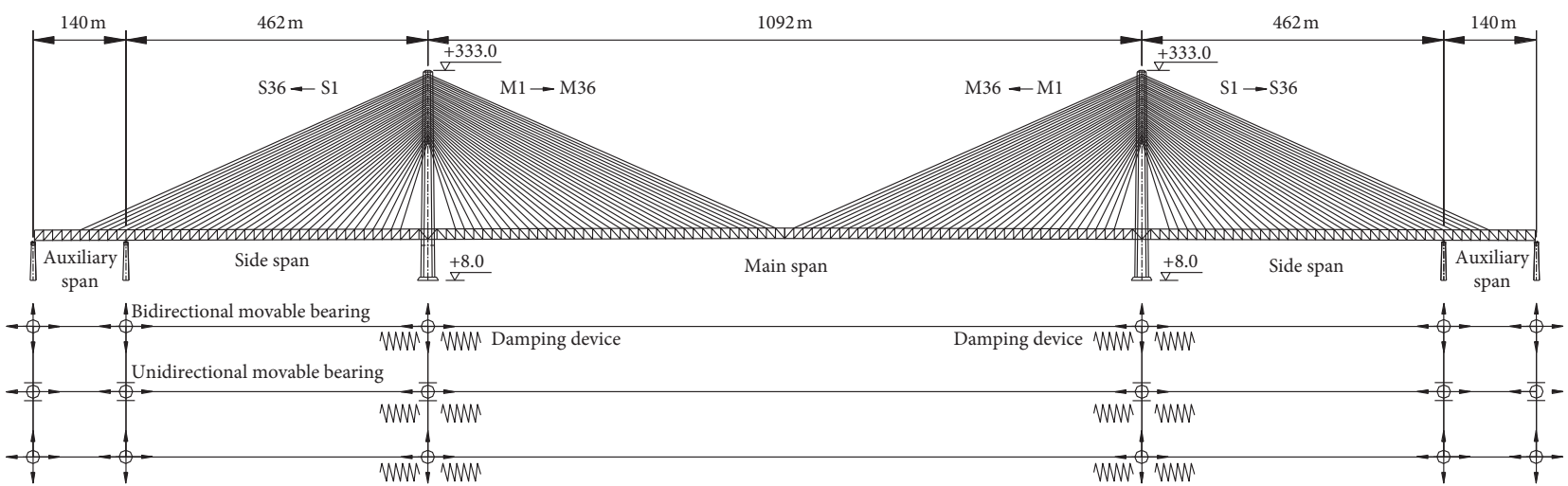

(a)

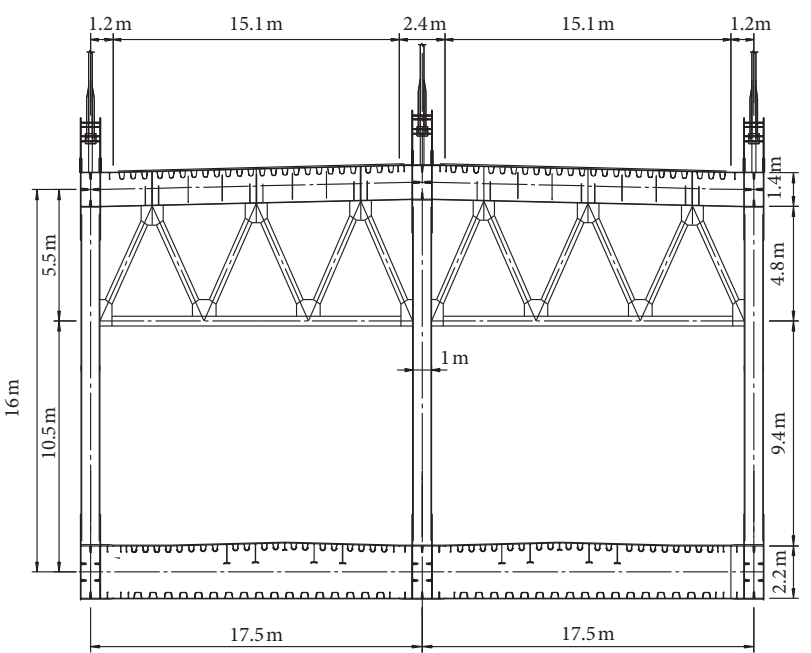

(b)

Figure 9: Profile of cable-stayed bridge. (a) General layout. (b) Cross section.

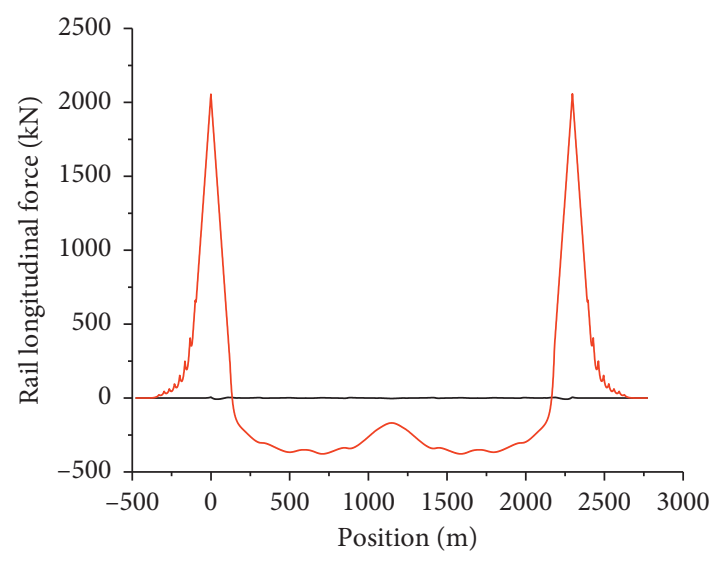

- New curve

Original curve

(a)

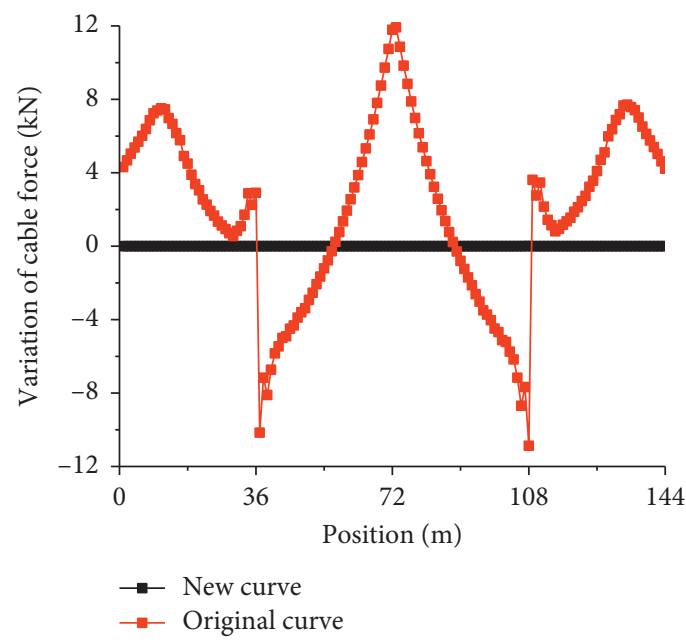

(b)

FIgURE 10: Results of completion calculation. (a) Rail longitudinal force. (b) Variation of cable force.

Table 1: Analysis state.

\begin{tabular}{lcc}
\hline No. & Abbr. & Analysis state \\
\hline 1 & SGN & Carefully considering GN and IIFs of the cable-stayed bridge \\
2 & L & Ignoring GN and IIFs of the cable-stayed bridge except the nonlinearity of the ballast longitudinal resistance \\
\hline
\end{tabular}




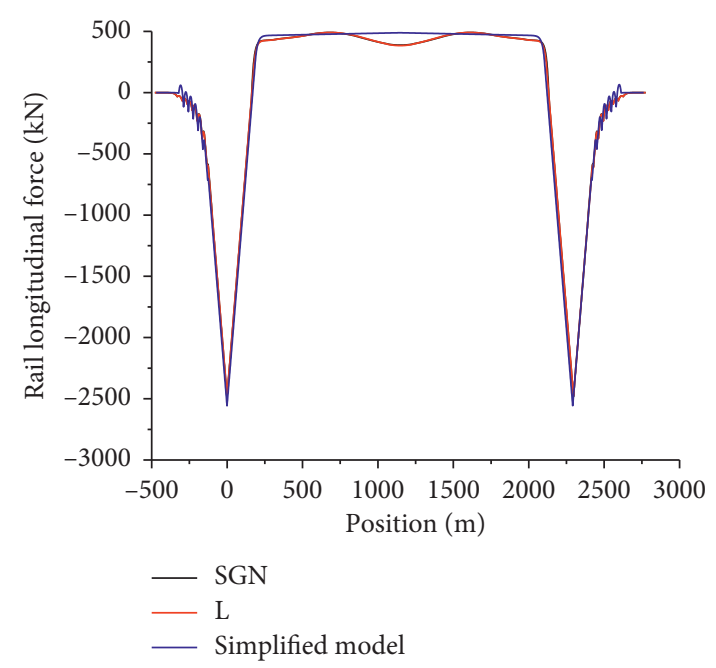

(a)

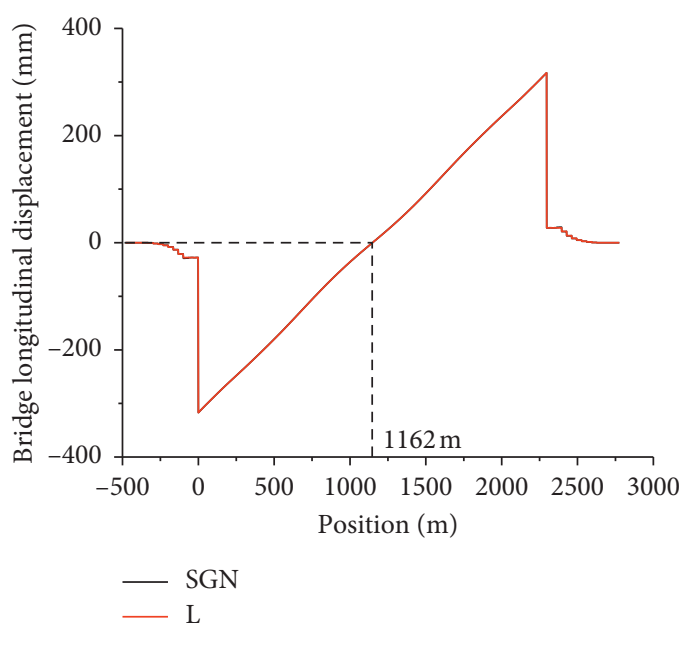

(b)

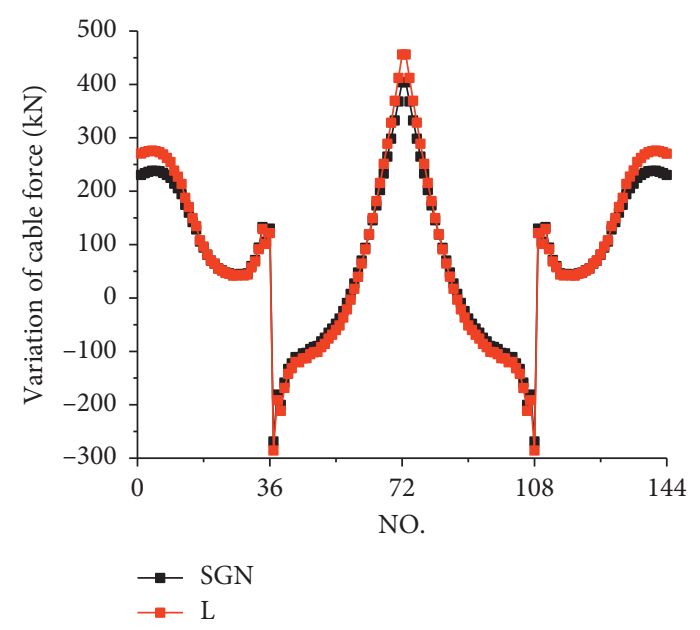

(c)

FIgURE 11: Results due to positive temperature changes in bridge decks. (a) Rail longitudinal force. (b) Bridge longitudinal displacement. (c) Variation of cable force.

respectively, compared to those corresponding to SNG and L analysis states. It will be safer to adopt the maximum force of the simplified model when designing CWR on the cablestayed bridge.

The GN and IIFs of the cable-stayed bridge considered in bridge-track interaction analysis have a great deal of impact on the bridge itself, as shown in Figure 11(c). In the SNG analytical state, the axial forces of all elements forming a stay cable are different due to cable sag effect. Therefore, the mean value is adopted as the force of a single stay cable for the SNG analysis. Figure 11(c) shows that the variations of cable force under the two analysis states are quite different due to effect of GN and IIFs, and the maximum difference is $52.0 \mathrm{kN}$, which is $12.9 \%$ of the corresponding SNG analytical state value.

In summary, in order to simplify the analysis of bridgetrack interaction of CWR on a cable-stayed bridge due to positive temperature changes in bridge decks, the impacts of GN and IIFs can be ignored, and the bridge can even be simplified as a two-span continuous beam bridge with a longitudinal constrain at the midspan and expandable beam ends at both sides. However, when the impact of bridgetrack interaction on the cable-stayed bridge needs to be analyzed, it is suggested that GN and IIFs of the bridge should be considered to ensure the accuracy of the calculated results.

4.2. Actions due to Vertical Bending of Bridge Deck under Train Load. The train load is applied on two of the four tracks of the railway. One railway should be used for CR live load, and the other for ZK live load. The two-line live loads are distributed within the main span of the bridge. If a train enters the bridge from the left side, the front of the train will be stopped at the right bridge tower and the back of the train will be stopped at the left bridge tower. The load length will be $1,092 \mathrm{~m}$. Figures 12 (a) and 12(b) show the rail longitudinal force and the variation of cable force obtained under SGN and $\mathrm{L}$ analysis states. 


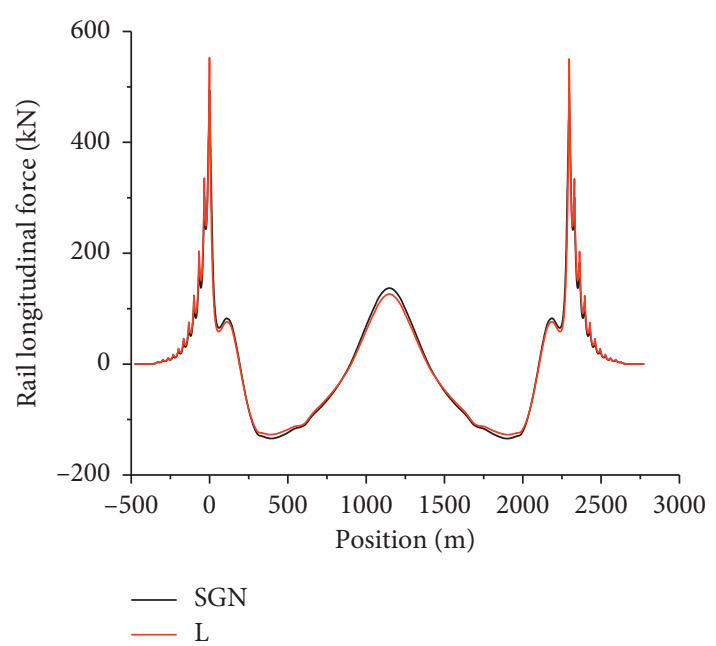

(a)

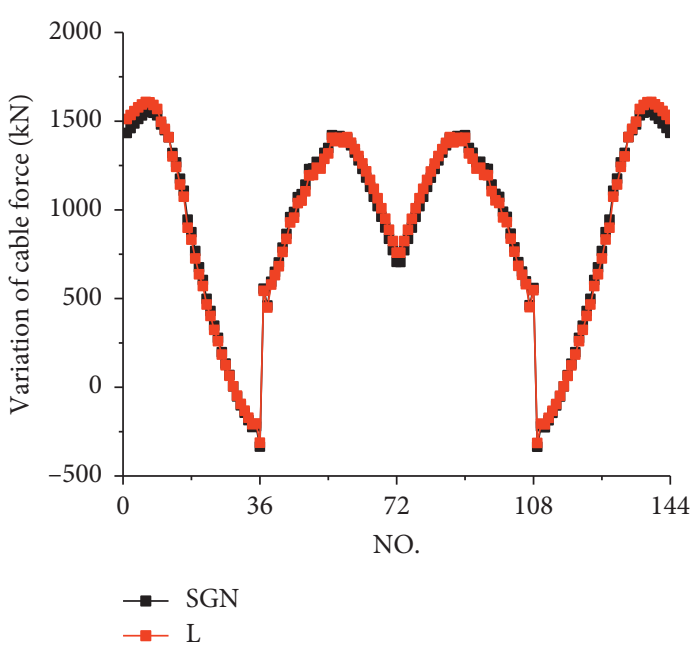

(b)

Figure 12: Results due to vertical bending of bridge deck under train load. (a) Rail longitudinal force. (b) Variation of cable force.

As shown in Figure 12(a), the distributions of rail longitudinal force corresponding to SGN and L analysis states are consistent. However, the difference in amplitudes is obvious. The maximum values of rail longitudinal tension force are $494.2 \mathrm{kN}$ and $552.6 \mathrm{kN}$, respectively, decreasing by $11.8 \%$ and exceeding the tolerated range of $5 \%-10 \%$ which is considered a permissible margin for civil engineering purposes. It can be seen that the bridge-track interaction can be relieved by the GN and IIFs of the bridge. From the design of CWR on the bridge, the rail longitudinal force obtained under $\mathrm{L}$ analytical state is higher, so it will also be safe to design CWR with it.

As shown in Figure 12(b), the variations of cable force obtained under SGN and L analysis states coincide with each other. The maximum amplitude difference is $78.1 \mathrm{kN}$, which is $5.5 \%$ of the value corresponding to the SNG analysis state. Thus, when the vertical bending of bridge deck under train load is considered, the GN and IIFs of the bridge have a little effect on the bridge itself.

In summary, when the vertical bending of bridge deck under train load is considered, the GN and IIFs of cablestayed bridge have significant effect on both bridge-track interaction and bridge structure. However, it will be safer to design CWR with the rail longitudinal force obtained under $\mathrm{L}$ analysis state.

4.3. Actions due to Breaking and Acceleration of Train. Two-line braking and two-line acceleration of train are adopted for CWR on the bridge. The positions of the braking and acceleration of train are also consistent. For a sample calculation, two railways are subject to CR live load. For the other two, ZK live load is adopted. The load length is $400 \mathrm{~m}$ and the wheel-rail adhesion coefficient is 0.164 [26]. When a train is braking, the front of train should be at the left end of the bridge. Otherwise, the back of the train should be at the left end of the bridge. Figures 13(a) and 13(b) show the rail longitudinal force and the variation of cable force when the damping devices between the beam and towers are still negligible.

As shown in Figure 13(a), the maximum rail longitudinal forces of SGN and L analysis states are $1,055.6 \mathrm{kN}$ and $1,033.5 \mathrm{kN}$, respectively. The difference between the two is only $22.1 \mathrm{kN}$, less than $2.1 \%$ of the maximum rail longitudinal force corresponding to the SNG analysis state. Accordingly, GN and IIFs of the cable-stayed bridge have little impact on the bridge-track interaction duo to breaking and acceleration of train. As shown in Figure 13(b), GN and IIFs also have little impact on the cable-stayed bridge.

When the effect of the damping devices between the steel truss and bridge towers is considered, the completion calculation of the cable-stayed bridge will also show no impact on the stress state of the damping devices. Therefore, it is also necessary to reconstruct new $D-F$ curves for the damping devices according to Section 1, as seen in

$$
F_{z}=k_{z}\left(D_{r}-b\right) \text {, }
$$

where $F_{z}$ is the longitudinal force corresponding to the damping device, $k_{z}$ is the stiffness of the damping device, $D_{r}$ is the relative displacement between a steel truss node and a bridge tower node that are connected with both ends of the damping device, and $b$ represents the relative displacement between both ends of the damping device caused by the completion calculation of the cable-stayed bridge.

Figure 14(a) shows the amplitude of rail longitudinal force due to breaking and acceleration of train when different stiffness values of damping devices are used.

As shown in Figure 14(a), as the stiffness of damping device increases, the amplitude of rail longitudinal force will decrease under SNG and L analysis states. However, the rate of change will gradually decrease. The amplitude difference of rail longitudinal force also decreases along with the increasing of stiffness; i.e., with the increase of the stiffness of the damping devices, the impact of GN and IIFs of cablestayed bridge on the bridge-track interaction will gradually decrease. According to the variation of cable force shown in 


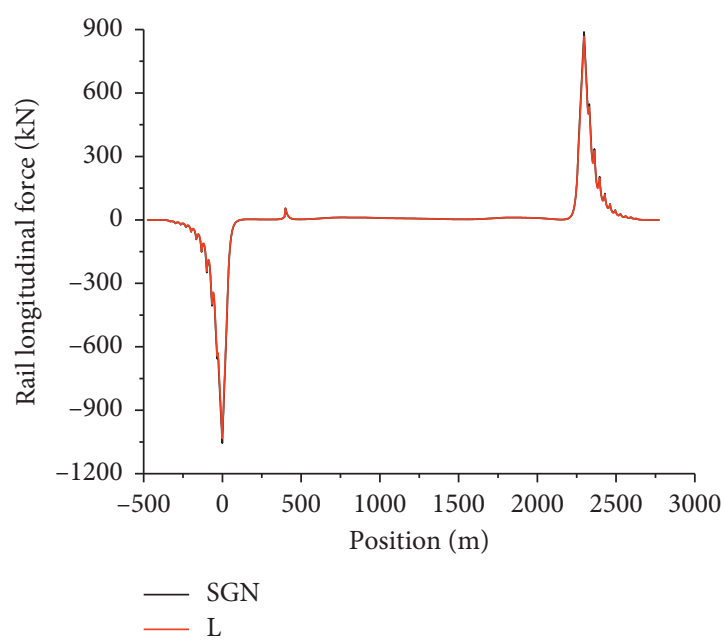

(a)

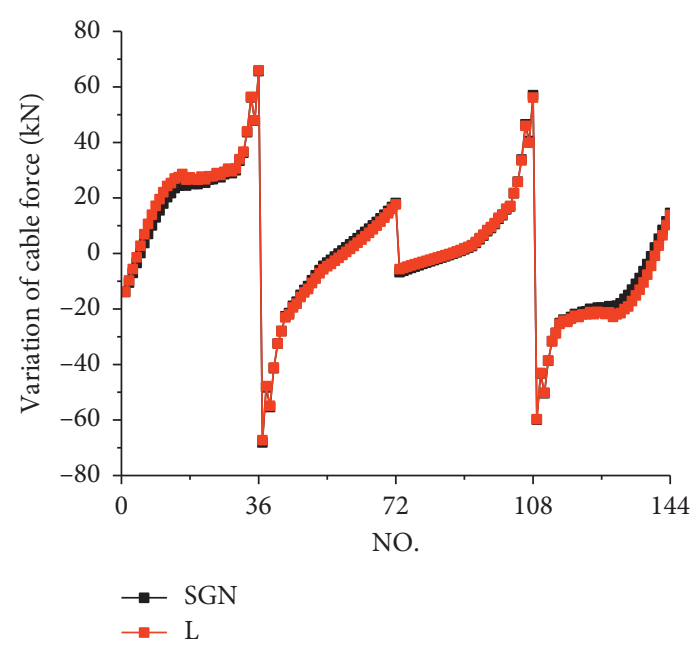

(b)

FIGURE 13: Results due to the breaking and acceleration of train. (a) Rail longitudinal force. (b) Variation of cable force.

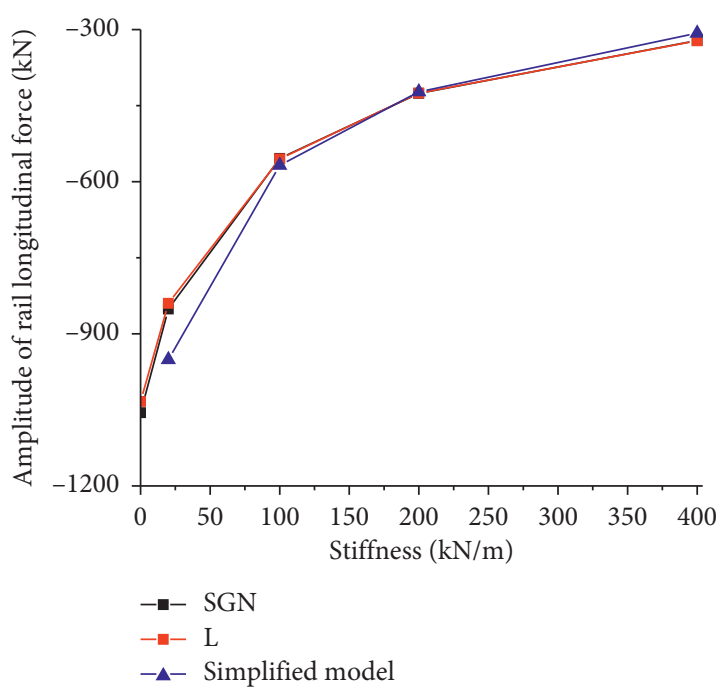

(a)

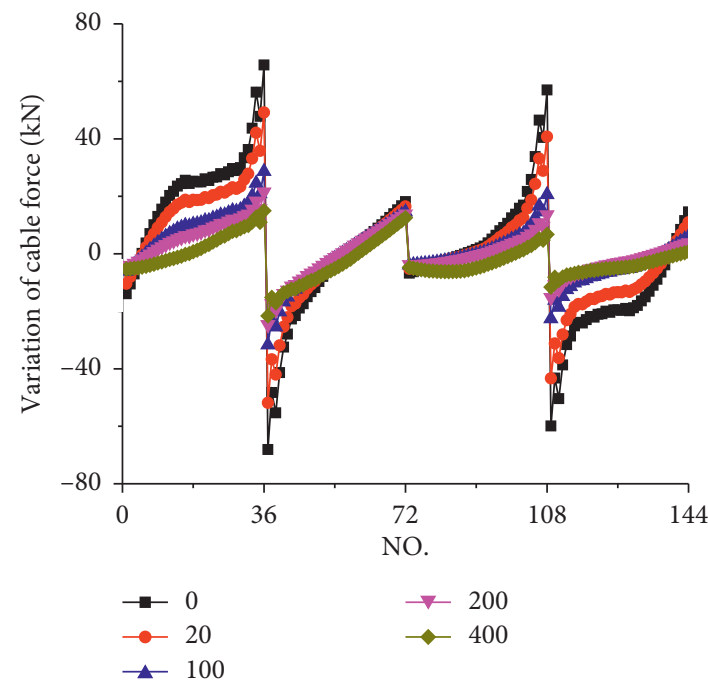

(b)

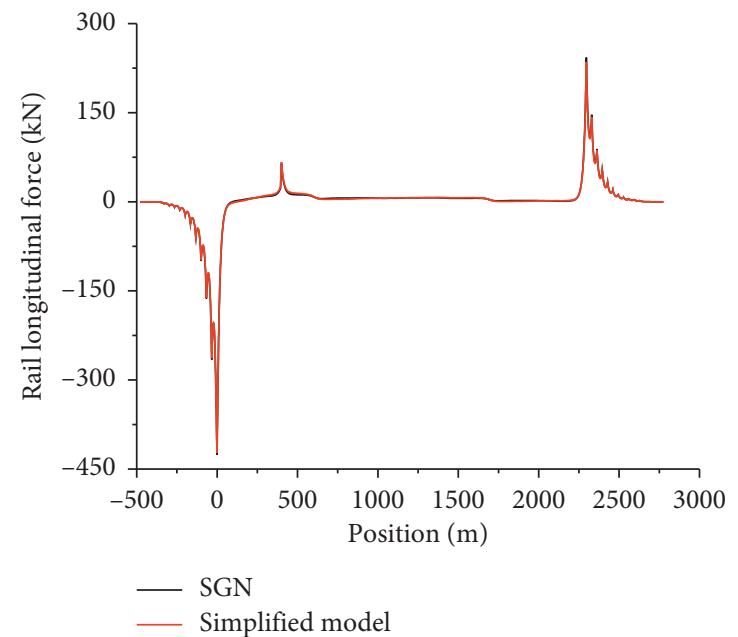

(c)

FIgURE 14: Results with damping devices. (a) Amplitude of rail longitudinal force. (b) Variation of cable force (SNG). (c) Rail longitudinal force. 


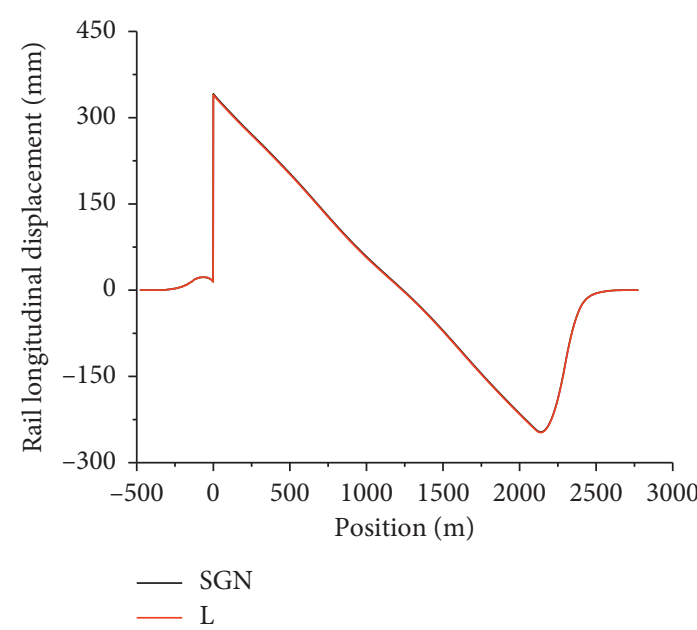

(a)

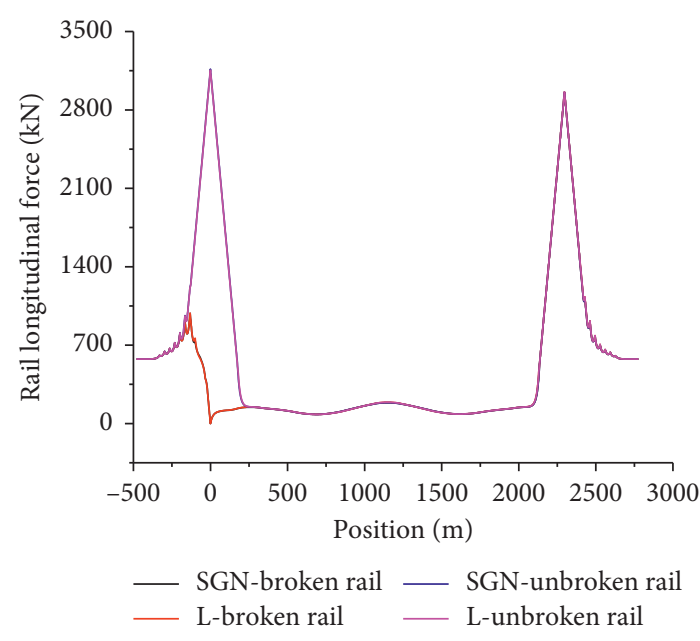

(b)

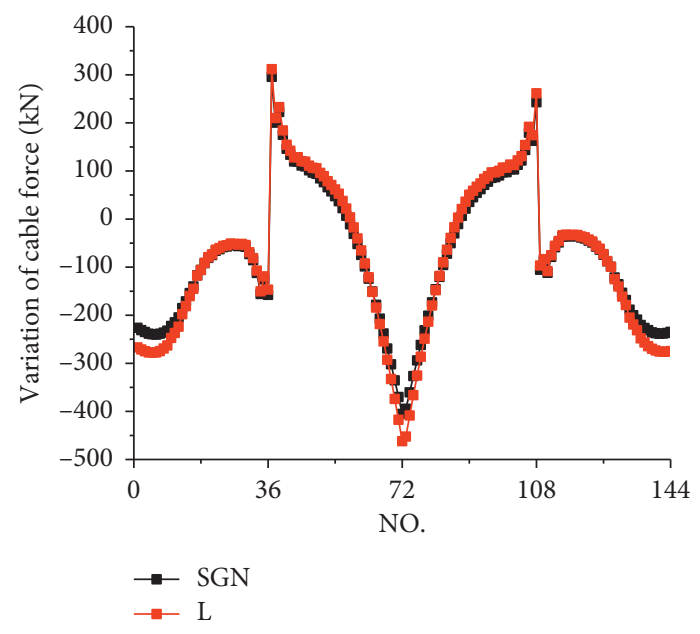

(c)

FIGURE 15: Results due to negative temperature changes in bridge decks and rails with rail breaking. (a) Rail longitudinal displacement. (b) Rail longitudinal force. (c) Variation of cable force.

Figure 14(b), with the increase of the stiffness of the damping device, the variation of cable force will decrease gradually.

Based on the above analysis, the bridge can be simplified as a continuous beam bridge, and its towers and damping devices can be simplified as linear springs connected in series. As the stiffness of the towers is higher than that of the damping devices, the simplified stiffness can be approximated to the stiffness of the damping devices according to (3). If the towers are of low stiffness, the simplified stiffness can be also calculated according to (3). The simplified continuous beam bridge will be freely and longitudinally expandable after the simplification has been completed.

$$
k_{j}=\frac{k_{z} \times k_{t}}{k_{z}+k_{t}}=\frac{k_{z}}{k_{z} / k_{t}+1} \approx k_{z}\left(k_{t} \gg k_{z}\right) \text {, }
$$

where $k_{j}$ is the simplified stiffness of springs and $k_{t}$ is the longitudinal stiffness of bridge towers connected to the damping devices.

Figure 14(c) shows the rail longitudinal force obtained from the simplified model. The distribution of rail longitudinal force coincides with that of the SNG analysis state. The difference in amplitude of rail longitudinal force is only $3.0 \mathrm{kN}$, verifying the simplified model as reasonable. The blue line in Figure 14(a) shows the amplitude of rail longitudinal force, when the stiffness of the damping devices changes within the simplified model. When the stiffness of the damping devices is low, the difference between the simplified model and the other two analysis states will be obvious because of the constraint of the stay cables.

In summary, the GN and IIFs of cable-stayed bridges have little impact on bridge-track interaction of CWR on cable-stayed bridges when breaking and acceleration of train are considered. A cable-stayed bridge can be simplified as a continuous beam bridge with expandable beam ends at both sides and longitudinal elastic constraint at bridge towers. The stiffness of longitudinal elastic constraint also can be simplified as the stiffness of damping devices.

4.4. Actions due to Negative Temperature Changes in Bridge Decks and Rails with Rail Breaking. The rail breaking 
position of CWR on a bridge is generally at the point with the maximum rail longitudinal force induced by the positive temperature changes in bridge decks. For the cable-stayed bridge, the rail breaking position is set at the left beam end of the bridge. The temperature of the main beam is decreased by $25 \mathrm{~K}$, the temperature of the concrete simple-supported beam bridge is decreased by $15 \mathrm{~K}$, and the temperature of the rail is decreased by $30 \mathrm{~K}$. Figures 15 (a) and 15 (b) show the rail longitudinal displacement and rail longitudinal force of the SNG and L analysis states.

As shown in Figure 15(a), the difference between the rail longitudinal displacement of the SNG and $\mathrm{L}$ analysis states is low. The rail broken gaps are $327.1 \mathrm{~mm}$ and $325.4 \mathrm{~mm}$, respectively, and the difference between the two rail broken gaps is only $1.7 \mathrm{~mm}$. According to Figure 15(b), the difference in rail longitudinal force of broken rail or unbroken rail remains low under the two analysis states. Therefore, the GN and IIFs of the cable-stayed bridge have little impact on the bridge-track interaction of CWR.

As shown in Figure 15(c), the distributions of variation of cable force under SNG and L analysis states are still consistent with one another; however, the amplitudes are different. The maximum difference can reach up to $58.8 \mathrm{kN}$, equivalent to $14.6 \%$ of the variation of cable force corresponding to the SNG analysis state. Therefore, when negative temperature changes in bridge decks and rails with rail breaking are considered, both GN and IIFs have a significant impact on the cable-stayed bridge.

In summary, the GN and IIFs of cable-stayed bridges have little impact on bridge-track interaction of CWR on cable-stayed bridges due to negative temperature changes in bridge decks and rails with rail breaking, but they have a significant impact on cable-stayed bridge itself.

\section{Conclusions}

A rail-beam-cable-tower 3D model is established with a new method for reconstructing the displacement-force curve of ballast longitudinal resistance. By taking a Chinese longspan cable-stayed bridge with length of main span exceeding $1,000 \mathrm{~m}$ as an example, a contrast analysis is carried out to study the impact of GN and IIFs on bridge-track interaction. The following can be concluded:

(1) It is proved that the method for reconstructing ballast longitudinal resistance makes it possible to consider the effect of IIFs of long-span cable-stayed bridge on bridge-track interaction by the numeric simulations.

(2) The GN and IIFs of cable-stayed bridge can relieve bridge-track interaction due to positive temperature changes in bridge decks and vertical bending of bridge deck under train load, but they aggravate the interaction due to breaking and acceleration of train and negative temperature changes in bridge decks and rails with rail breaking. The two factors have little influence on the rail longitudinal force induced by positive temperature changes in bridge decks and breaking and acceleration of train, and rail breaking gap, but they reduce the amplitudes of rail longitudinal force induced by vertical bending of bridge deck under train load by $11.8 \%$.

(3) The bridge-track interaction of CWR on cable-stayed bridge can change cable force, especially due to positive temperature changes in bridge decks and negative temperature changes in bridge decks and rails with rail breaking. The GN and IIFs of cablestayed bridge also have effect on cable force. In particular, when breaking and acceleration of train are considered, the two factors can reduce the variance of cable force by $14.6 \%$.

(4) The GN and IIFs of cable-stayed bridge can be neglected, and the cable-stayed bridge can even be simplified as a continuous beam bridge with expandable beam ends at both sides, when the rail longitudinal force due to positive temperature changes in bridge decks or breaking and acceleration of train is calculated. If rail longitudinal force due to positive temperature changes in bridge decks is calculated, the midspan of continuous beam bridge must be fixed. While rail longitudinal force due to breaking and acceleration of train is calculated, the longitudinal stiffness of tower and damping devices should be considered.

\section{Data Availability}

The data used to support the findings of this study are included within the article.

\section{Conflicts of Interest}

The authors declare that there are no conflicts of interest regarding the publication of this paper.

\section{Acknowledgments}

The authors thank the fund support by the National Natural Science Foundation of China (Nos. 51978423 and 51778050), the National Natural Science Foundation of Hebei Province (No. E2019210185), the Youth Foundation of Hebei Educational Committee (No. QN2019124), and Beijing Engineering and Technology Research Center of Rail Transit Line Safety and Disaster Prevention Open Foundation for Research (No. RRC201901).

\section{References}

[1] B. Sun, J. Cheng, and R. C. Xiao, "Preliminary design and parametric study of $1,400 \mathrm{~m}$ partially earth-anchored cablestayed bridge," Science China Technological Sciences, vol. 53, no. 2, pp. 502-511, 2010.

[2] M. Nagai, Y. Fujino, H. Yamaguchi, and E. Iwasaki, "Feasibility of a 1,400 m span steel cable-stayed bridge," Journal of Bridge Engineering, vol. 9, no. 5, pp. 444-452, 2004.

[3] X. J. Zhang and H. L. Sun, "Study of the aerostatic and aerodynamic stability of super long-span cable-stayed bridges," Engineering Sciences, vol. 16, no. 2, pp. 82-92, 2014. 
[4] X. H. He, T. Wu, Y. F. Zou, Y. F. Chen, H. Guo, and Z. W. Yu, "Recent developments of high-speed railway bridges in China," Structure and Infrastructure Engineering, vol. 13, no. 12, pp. 1584-1595, 2017.

[5] J. F. Fleming, "Nonlinear static analysis of cable-stayed bridge structures," Computers \& Structures, vol. 10, no. 4, pp. 621-635, 1979.

[6] J. A. Zakeri, M. M. Feizi, M. Shadfar, and M. Naeimi, "Sensitivity analysis on dynamic response of railway vehicle and ride index over curved bridges," Proceedings of the Institution of Mechanical Engineers, Part K: Journal of MultiBody Dynamics, vol. 231, no. 1, pp. 266-277, 2016.

[7] J. A. Zakeri and M. R. Tajalli, "Comparison of linear and nonlinear behavior of track elements in contact-impact models," Periodica Polytechnica Civil Engineering, vol. 62, no. 4, pp. 963-970, 2018.

[8] H. Xia, Y. Xu, T. Chan, and J. A. Zakeri, "Dynamic responses of railway suspension bridges under moving trains," Scientia Iranica, vol. 14, no. 5, pp. 385-394, 2007.

[9] N. Mirković, Z. Popović, A. P. Pustovgar, L. Lazarević, and A. V. Zhuravlev, "Management of stresses in the rails on railway bridges," FME Transactions, vol. 46, no. 4, pp. 636643, 2018.

[10] P. Ruge and C. Birk, "Longitudinal forces in continuously welded rails on bridge decks due to nonlinear track-bridge interaction," Computers \& Structures, vol. 85, no. 7-8, pp. 458-475, 2007.

[11] K. Z. Xie, P. Wang, L. Wang, and R. Chen, "Impact of seismic effects on rail expansion joints on bridge," Journal of the China Railway Society, vol. 38, no. 3, pp. 111-118, 2016.

[12] M. P. Petrangeli, “The Italian experience: two case studies," in Track-Bridge Interaction on High-Speed Railways, R. Calcada, R. Delgado, and A. C. E. Matos, Eds., CRC Press, Boca Raton, FL, USA, 2009.

[13] P. Wang, W. H. Zhao, R. Chen, and J. L. Xiao, "Bridge-rail interaction for continuous welded rail on cable-stayed bridge due to temperature change," Advances in Structural Engineering, vol. 16, no. 8, pp. 1347-1354, 2013.

[14] P. Wang, H. Liu, X. K. Wei, and J. L. Xiao, "Analysis of longitudinal force regulation for CWR on railway cablestayed bridge," Journal of Traffic and Transportation Engineering, vol. 13, no. 5, pp. 27-32, 2013.

[15] W. H. Zhao, P. Wang, and Y. Cao, "Calculation of braking force of continuous welded rail on large-span steel truss cablestayed bridge," Journal of Southwest Jiaotong University, vol. 47, no. 3, pp. 361-366, 2012.

[16] G. L. Dai and B. Yan, "Longitudinal forces of continuously welded track on high-speed railway cable-stayed bridge considering impact of adjacent bridges," Journal of Central South University, vol. 19, no. 8, pp. 2348-2353, 2012.

[17] B. Yan and G. L. Dai, "Analysis of interaction between continuously-welded rail and high-speed railway bridge considering loading-history," Journal of the China Railway Society, vol. 36, no. 6, pp. 75-80, 2014.

[18] P. F. Zheng, B. Yan, and G. L. Dai, "Rail broken gap study on continuous welded rail on cable-stayed bridge of high-speed railway," Journal Of Huazhong University Of Science And Technology, vol. 40, no. 9, pp. 85-88, 2012.

[19] J. Zheng, D. J. Wu, and Q. Li, "Loading-history-based trackbridge interaction analysis with experimental fastener resistance," Engineering Structures, vol. 83, no. 1, pp. 62-73, 2015.

[20] Y. Li, "Study on variation rules of longitudinal force of continuous welded rails on long-span cable-stayed bridge,"
Journal of Railway Engineering Society, vol. 29, no. 10, pp. 42-46, 2012.

[21] X. P. Cai, Q. Miao, D. C. Li, and J. J. Xu, "Mechanical analysis and arrangement study of REJ for CWR on cable-stayed bridge," Journal of Railway Engineering Society, vol. 35, no. 1, pp. 36-41, 2018.

[22] P. H. Wang, T. C. Tseng, and C. G. Yang, "Initial shape of cable-stayed bridges," Computers \& Structures, vol. 46, no. 6, pp. 1095-1106, 1993.

[23] J. Wu, D. M. Frangopol, and M. Soliman, "Geometry control simulation for long-span steel cable-stayed bridges based on geometrically nonlinear analysis," Engineering Structures, vol. 90, no. 5, pp. 71-82, 2015.

[24] P. Yuan, D. J. Li, C. X. Li, and C. Y. Luo, "Study of spatial conditions of steel box girder cable-stayed bridge with four cable planes under reasonable completed bridge state," Bridge Construction, vol. 46, no. 1, pp. 47-52, 2016.

[25] Z. Popović, L. Lazarević, M. Vilotijević, and N. Mirković, "Interaction phenomenon between train, track and bridge," in Energy Management of Municipal Transportation Facilities and Transport, V. Murgul and Z. Popovic, Eds., pp. 3-11, Springer, Berlin, Germany, 2017.

[26] Ministry of Railways of the People's Republic of China, TB10015-2013 Code for Design of Railway Continuous Welded Rail, China Railway Publishing House, Taiyuan, China, 2012.

[27] K. J. Bathe and S. Bolourchi, "Large displacement analysis of three-dimensional beam structures," International Journal for Numerical Methods in Engineering, vol. 14, no. 7, pp. 961-986, 1979. 